\title{
Kinetics of electrocrystallisation of $\mathrm{PbO}_{2}$ on glassy carbon electrodes: influence of ultrasounds
}

\author{
J. González-García*a , F. Gallud*, J. Iniesta*, V. Montiel*, A. Aldaz* and A. Lasia** \\ *Grupo de Electroquímica Aplicada, Departamento de Química Física \\ Universidad de Alicante, Ap. Correos 99. 03080 Alicante, Spain \\ **Département de Chimie, Université de Sherbrooke, Sherbrooke, P.Q., J1K 2R1, \\ Canada
}

\begin{abstract}
Electrocrystallisation of lead dioxide on glassy carbon electrodes was studied in $1 \mathrm{M} \mathrm{HNO}_{3}+0.1 \mathrm{M} \mathrm{Pb}\left(\mathrm{NO}_{3}\right)_{2}$ in the presence of ultrasounds using chronoamperometry and scanning electron microscopy. In order to compare these results with those obtained in the absence of ultrasounds, numerical approximations of the current transients have been carried out. Results obtained can be explained assuming formation of a soluble intermediate.
\end{abstract}

Key words: ultrasounds, lead dioxide, glassy carbon electrodes, sono-voltammetry, sono-electrochemistry, electrodeposition.

\section{INTRODUCTION}

In the recent years sonoelectroelectrochemistry has become an active research field [1]. Recent [2, 3] and older reviews [4, 5] have pointed out the benefits of an ultrasonic field on the electrode processes. Effects of ultrasounds have been observed on the mass transport to the electrode [6-8], activation of the electrode surface [9], on adsorption processes [10], on the reaction path by generation of radicals [11], etc. In

\footnotetext{
${ }^{\text {a }}$ Corresponding author:jose.gonzalez@ua.es
} 
this context, we can expect that the application of ultrasounds will be useful in the development of the new and/or improvement of the actual methods.

Electrocrystallisation of lead dioxide was first investigated by Fleischmann et al. [12-15] who suggested the existence of insoluble intermediates adsorbed on the electrode. Further works have focused their attention on the nature of the intermediates [16-19], and soluble intermediates have been detected. Recently, Velichenko et al. [2022] have proposed a new mechanism involving soluble intermediates:

$$
\begin{gathered}
\mathrm{H}_{2} \mathrm{O} \rightarrow \mathrm{OH}_{\mathrm{ads}}+\mathrm{H}^{+}+\mathrm{e}^{-} \\
\mathrm{Pb}^{2+}+\mathrm{OH}_{\mathrm{ads}} \rightarrow \mathrm{Pb}(\mathrm{OH})^{2+} \\
\mathrm{Pb}(\mathrm{OH})^{2+}+\mathrm{H}_{2} \mathrm{O} \rightarrow \mathrm{PbO}_{2}+3 \mathrm{H}^{+}+\mathrm{e}
\end{gathered}
$$

Electrodeposition of lead dioxide on glassy carbon electrodes under ultrasounds has been recently studied in our laboratory [23] and a strong influence of the ultrasonic field on the process was observed. The present paper studies the nucleation and growth of the lead dioxide in the presence of ultrasounds and it is a continuation of our previous works where the lead dioxide electrocrystallisation was studied in the absence of ultrasounds [24] in a stagnant solution and in the presence of forced convection on a rotating disk electrode [25]. The classical models [26-28] have been used to obtain the kinetics parameters of the processes $\left(\mathrm{N}_{0}, \mathrm{~A}, \mathrm{k}\right)$ and to quantify the influence of the ultrasonic field on the process mechanism.

\section{EXPERIMENTAL SECTION}

A standard two-compartment electrochemical cell with a volume of $50 \mathrm{~mL}$ was used in the experiments. The chemicals were Analar quality and were used as received. 
The cell was filled with an aqueous solutions of $0.1 \mathrm{M}$ lead(II) nitrate $+1 \mathrm{M}$ nitric acid, prepared using ultrapure water from a Millipore Milli-Q system. A platinum wire acted as the counter electrode. A SCE served as the reference electrode.

The working electrode was a glassy carbon rod (diam. $3 \mathrm{~mm}$ ) CV25 from Sofacel (Le Carbone-Lorraine). Before each experiment, the glassy carbon electrode was polished first with fine emery paper, followed by polishing with decreasing size alumina particles in suspension, on a polishing cloth, until a mirror finish was obtained. After that the electrode was thoroughly rinsed with water.

A Selecta commercial ultrasonic bath $(30 \mathrm{kHz}-100 \mathrm{~W})$ was employed in the sonoelectrochemical experiments. The system was maintained at a constant temperature of $25^{\circ} \mathrm{C}$ using a thermostat Model Frigiterm-30 (Selecta). The electrochemical cell was positioned just over the transducer of the ultrasonic bath. The cell was immersed in such a way that the levels of both liquids (bath and electrolyte) were the same. The separation between the transducer and the electrode surface was $6 \mathrm{~cm} \mathrm{[23].}$

Solutions were thoroughly purged of oxygen prior to running the experiment by bubbling with Nitrogen N50 (Air Liquide) for 20 minutes. Nitrogen N50 (Air Liquide) was also used for saturation of the solutions before each experiment. During the measurements a flow of gas was maintained over the solution surface. Lead dioxide deposits were removed from the surface with $1: 1 \mathrm{H}_{2} \mathrm{O}_{2}$ /Acetic acid mixture followed by rinsing with water.

All experiments were carried out using a Voltalab Electrochemical system consisting of a DEA 332 potentiostat and an IMT 102 Electrochemical Interface. The system was connected to a personal computer for recording and treatment of curves. 
A JSM-840 JEOL Scanning electron microscope was employed to obtain topographical views of the electrodes surfaces.

\section{RESULTS}

Figure 1 shows the $\mathrm{j}$-t transients for lead dioxide electrodeposition at a glassy carbon rod electrode under ultrasonic conditions. The curve shapes were different from those obtained with the same electrode in the absence of ultrasounds (taken from reference 24), several curves are compared in Figure 2. A strong decrease of the induction time and a great enhancement of the steady state current density is observed in the presence of ultrasounds as compared to silent conditions. Therefore, ultrasounds present additional effects to those expected from pure convection [18, 25], because the experimental curves are absolutely different. Besides, the peak obtained in the absence of ultrasounds on $\mathrm{j}$ - $\mathrm{t}$ transients, disappeared under ultrasounds (see the curves at $\mathrm{E}_{\mathrm{f}}$ $=1540 \mathrm{mV}$ vs. SCE).

Figure 3 shows the SEMs of the lead dioxide electrodeposition in the early stages of the electrocrystallisation. In the SEM micrograph, Figure 3a, one can clearly see different sizes of the nuclei, which suggests a progressive nucleation mechanism. Photograph $3 \mathrm{~b}$ shows morphology of the nuclei in detail. The topography of the single crystals is much more irregular that for the crystals obtained in the absence of ultrasounds [24] at the same substrate.

To explain the crystal growth, a model described by Eq. 4 was used. This equation corresponds to a simple progressive 3D nucleation and crystal growth model with the outward growth on a substrate base plane surface not covered by growing nuclei. This model was also used in the studies on the rotating disk electrode [25]: 


$$
\mathrm{j}=\mathrm{j}_{0} \exp \left[-\frac{\pi \mathrm{M}^{2} \mathrm{k}^{2} \mathrm{~N}_{0} \mathrm{~A}}{3 \rho^{2}}\left(\mathrm{t}-\mathrm{t}_{0}\right)^{3}\right]+\mathrm{zFk}\left[1-\exp \left[-\frac{\pi \mathrm{M}^{2} \mathrm{k}^{2} \mathrm{~N}_{0} \mathrm{~A}}{3 \rho^{2}}\left(\mathrm{t}-\mathrm{t}_{0}\right)^{3}\right]\right]
$$

This equation contains four parameters: $\mathrm{t}_{0}(\mathrm{~s})$, the induction time, $\mathrm{j}_{0}\left(\mathrm{~mA} \mathrm{~cm}^{-2}\right)$, the current density in the induction time, $\mathrm{k}\left(\mathrm{mol} \mathrm{cm} \mathrm{cm}^{-1}\right)$, constant of the growth rate, and $\mathrm{N}_{0} \mathrm{~A}$ (nuclei $\mathrm{cm}^{-2} \mathrm{~s}^{-1}$ ), constant of the three-dimensional nucleation. However, $\mathrm{j}_{0}$ is not very important in the whole approximation and the rate constant $\mathrm{k}$ is clearly determined when a well-defined current density plateau exists. The results of the approximations are presented in Fig 4 and in Table 1. With the increase of the applied potential $\mathrm{N}_{0} \mathrm{~A}$ increases, induction time decreases, in agreement with the literature [12, 29], and the growth constant seems to be a constant except the most negative potential.

\section{DISCUSSION}

Figure 5 shows the influence of the potential step on the induction time, nucleation constant and growth constant in presence and absence of ultrasound. There is a clear influence of the ultrasonic field on the process, stronger at lower potentials. The most marked effect is the decrease of the induction time. This phenomenon was already pointed out in our previous work [23] and can be associated with the surface fuctionalisation caused by the reaction of $\mathrm{OH}^{-}$radicals (derived from aqueous sonolysis) with the carbon surface. This enhanced adsorption must increase the number of the active sites on the surface (possible nucleation centres), and therefore, decrease the time necessary for stabilisation of nuclei during early stages of deposition, i.e. decrease the induction time. Other notorious effect is the increase in the steady state current density, that is the growth rate constant. The observed effect is fast growth of nucleation centres. Centres, which are formed, grow more quickly, although their number is lower than in the absence of ultrasounds. 
It is known that, under these experimental conditions $(\mathrm{Pb}(\mathrm{II})$ concentration and $\mathrm{pH})$ the forced convection conditions using rotating disk electrode do not enhance the electrocrystallisation of lead dioxide $[18,19,25]$. An ultrasonic field presents an inherent enhancement of the convection. Therefore, the ultrasounds present a wide range of effects, both beneficiary and disadvantageous, which balance the experimental results. Taking into a account the mechanism suggested by Velichenko et al. [20-22], ultrasounds seems to activate every mechanism steps: enhance the OH'adsorption, e. g. a higher $\left[\mathrm{OH}_{\mathrm{ads}}\right]$ is obtained at shorter times. Higher $\left[\mathrm{OH}_{\mathrm{ads}}\right]$ concentration accelerates the step 2. In this context, if the results obtained under ultrasonic conditions are opposite to the results in forced convection conditions, ultrasounds must increase the rate of the step 3 in order to reduce the half-life time of the soluble intermediate species, avoiding removal of the soluble intermediate from the electrode surface. However, confirmation of such an acceleration of step 3 needs further experimental work. Other possibility would be a new reaction mechanism in the presence of ultrasounds, often observed in organic electrosynthesis [30, 31].

Lower nucleation rate constant observed in the presence of ultrasounds can be related to the fact that the electrocrystallisation is easier on the same substrate $\left(\mathrm{PbO}_{2}\right)$ than on the other material (glassy carbon) [29, 32]. At higher potentials, the crystal growth can be inhibited [24] and one possible explanation could be the descomposition $\mathrm{OH}_{\mathrm{ads}}$ into $\mathrm{O}_{\mathrm{ads}}$ and $\mathrm{H}^{+}$(in this potential range), as pointed out by other authors [33]. Further work with a commercial ultrasonic probe system is currently in progress in order to deliver ultrasounds directly into the system, rather than rely on its transfer though the water of a tank and the voltammetric cell walls.

\section{CONCLUSIONS}

The application of an ultrasonic field on the electrocrystallisation of lead dioxide onto glassy carbon presents marked effects: 
- This process is a good example of the specific effects of ultrasounds, different from enhancement of mass transport, through surface activation, radical formation, etc., because the experimental results are very different from those obtained from RDE experiments.

- The comparison of the values of the kinetic parameters obtained in presence and absence of ultrasounds, suggests that after the nuclei become stable during the induction time, ultrasounds enhance the growth of the already formed nuclei without acceleration of the nucleation rate $\mathrm{N}_{0} \mathrm{~A}$. This observation can be supported from the topology of the nuclei by means of the SEM.

\section{ACKNOWLEDGMENT}

The authors would like to thank "Ministerio de Ciencia y Tecnología" for their financial support under project BQU2000-0460.

\section{References}

[1] V. Yegnaraman and S. Bharathi, Bull. Electrochem. 1992, 8, 84.

[2] R. G. Compton, J. C. Eklund, F. Marken, T. O. Rebbitt, R. P. Akkermans and D. N. Waller, Electrochim. Acta. 1997, 42, 2919.

[3] R. G. Compton, J. C. Eklund and F. Marken, Electroanalysis. 1997, 9, 509.

[4] E. Yeager and F. Hovorka, J. Acoust. Soc. Amer., 1953, 25443.

[5] R. Zana and E. Yeager in Modern Aspects of Electrochemistry, J.O'M Bockris, B. E. Conway and R. E. White (eds). Plenum Press 1979, vol 14, Cap. 1.

[6] E. Kowalska and J. Mizera, Ultrasonics 1971, 9, 81.

[7] J. P. Lorimer, B. Pollet, S. S. Phull, T. J. Mason, D. J. Walton and U. Geissler, Electrochim. Acta, 1996, 41, 2737.

[8] R. G. Compton, J. C. Eklund, S. D. Page, T. J. Mason and D. J. Walton, J. Appl. Electrochem. 1996, 26, 775. 
[9] R. G. Compton, J. C. Eklund, S. D. Page, G. H. W. Sanders and J. Booth, J. Phys. Chem. 1994, 98, 12410.

[10] D. J. Walton, S. S. Phull, A. Chyla, J. P. Lorimer, T. J. Mason, L. D. Burke, M. Murphy, R. G. Compton, J. C. Eklund and S. D.; Page, J. Appl. Electrochem. 1995, 25, 1083.

[11] R. G. Compton and F. M. Matysik, Electroanalysis. 1996, 8, 218.

[12] M. Fleischmann and M. Liler Trans. Faraday Soc. 1958, 54, 1370.

[13] M. Fleischmann and H. R. Thirsk, Electrochim. Acta. 1959, 1, 146.

[14] M. Fleischmann and H. R. Thirsk, Electrochim. Acta. 1960, 2, 22.

[15] M. Fleischmann, J. R. Mansfield, H. R. Thirsk, H. G. E. Wilson and L. WynneJones, Electrochim. Acta. 1967, 12, 967.

[16] H. A. Laitinen and N. H. Watkins, J. Electrochem. Soc. 1976, 123, 804.

[17] S. A. Campbell and L. M. Peter, J. Electroanal. Chem. 1991, 306, 185.

[18] H. Chang and D. C. Johnson, J. Electrochem. Soc. 1989, 136, 17.

[19] H. Chang and D. C. Johnson, J. Electrochem. Soc. 1989, 136, 23.

[20] A. B. Velichenko, D. V. Girenko and F. I. Danilov, Electrochim. Acta. 1995, 40, 2803.

[21] A. B. Velichenko, D. V. Girenko and F. I. Danilov, J. Electroanal. Chem. 1996, 405, 127.

[22] A. B. Velichenko, S. V. Kovalyov, A. N. Gnatenko, R. Amadelli, D. V. Girenko and F. I. Danilov, Electrochim. Acta. 1998, 454, 205.

[23] J. González-García, J. Iniesta, A. Aldaz and V. Montiel, New J. Chem. 1998, 22, 343.

[24] J. González-García, F. Gallud, J. Iniesta, M. Montiel, A. Aldaz and A. Lasia, J. Electrochem. Soc. 2000, 147, 2969.

[25] J.González-García, F. Gallud, J. Iniesta, M. Montiel, A. Aldaz and A. Lasia, Electroanalysis in press.

[26] J. A. Harrison and H. R. Thirsk, in Electroanalytical Chemistry, Bard, A. J. Ed.; Marcel Dekker: London, 1971, p. 67. 
[27] M. Fleischmann and H. R. Thirsk, In Advances in Electrochemistry and Chemical Engineering; Delahay, P.; Tobias, C. W. Eds.; Willey Interscience: New York, 1963, Vol. 3, pp-123-210.

[28] J. A. Harrinson and H. R. Thirsk, In A guide to the Study of the Electrode Kinetics; Academic Press: New York, 1972, Cp.3.

[29] A. C. Ramamurthy and T. Kuwana, J. Electroanal. Chem., 1982, 135, 243

[30] G. E. Hawkes, J. H. P. Utley and G. B. Yates, J. Chem. Soc. Perkin Trans. 1976, $2,1709$.

[31] D. J. Walton, A. Chyla, J. P. Lorimer, T. J. Maso and G. Smith, J. Chem. Soc., Chem. Commun., 1989, 603.

[32] D. Velayutham and M. Noel, Electrochim. Acta 1991, 36, 2031.

[33] J. Lee, H. Valera, S. Uhm and Y. Tak, Electrochemistry Commun. 2000, 2, 646. 


\section{Captions}

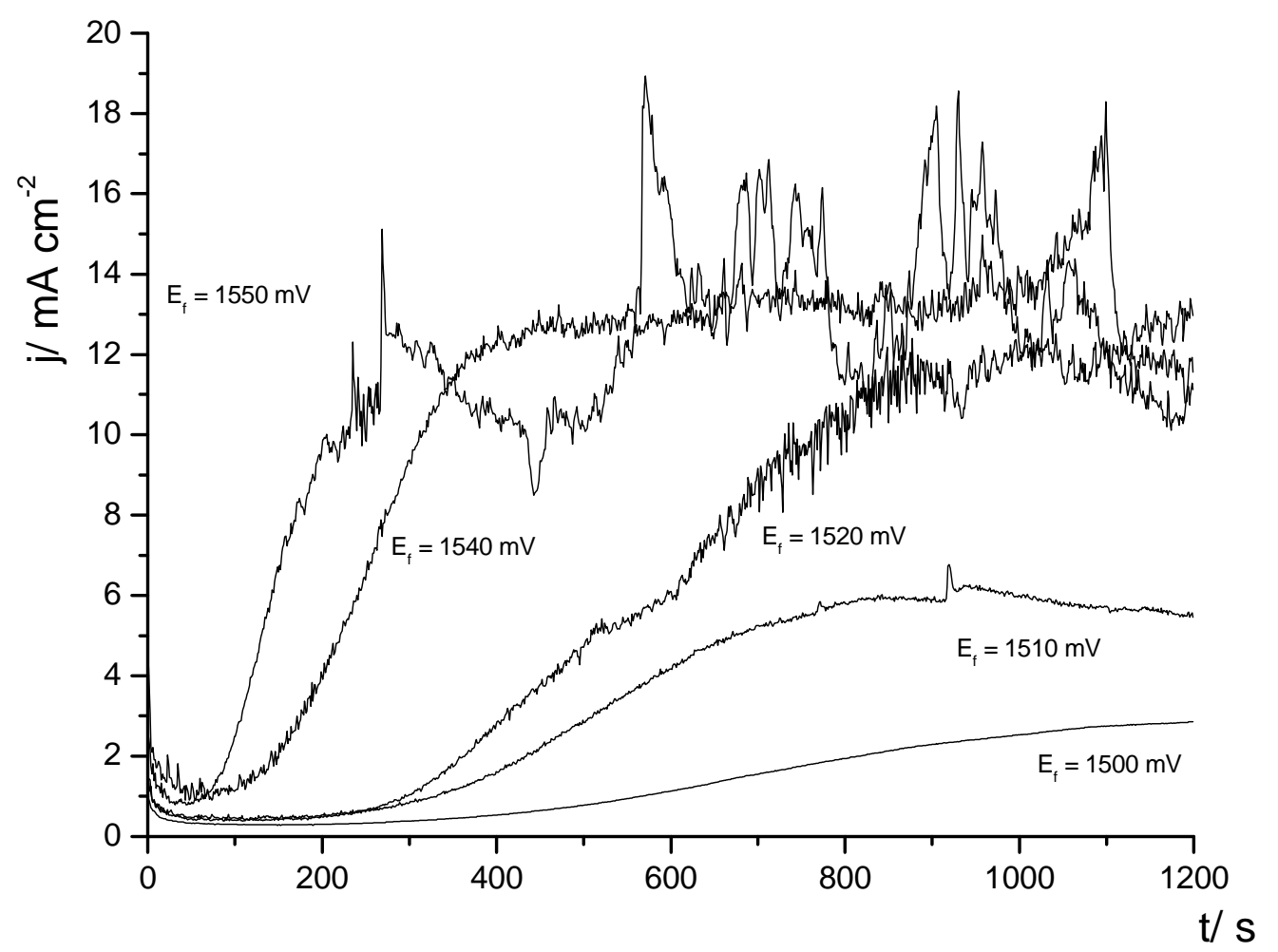

Figure 1.- Chronoamperometric curves for $\mathrm{PbO}_{2}$ deposition in $0.1 \mathrm{M} \mathrm{Pb}\left(\mathrm{NO}_{3}\right)_{2}+1 \mathrm{M}$ $\mathrm{HNO}_{3}$ at a glassy carbon electrode in ultrasonic conditions (Potential steps in figure). 


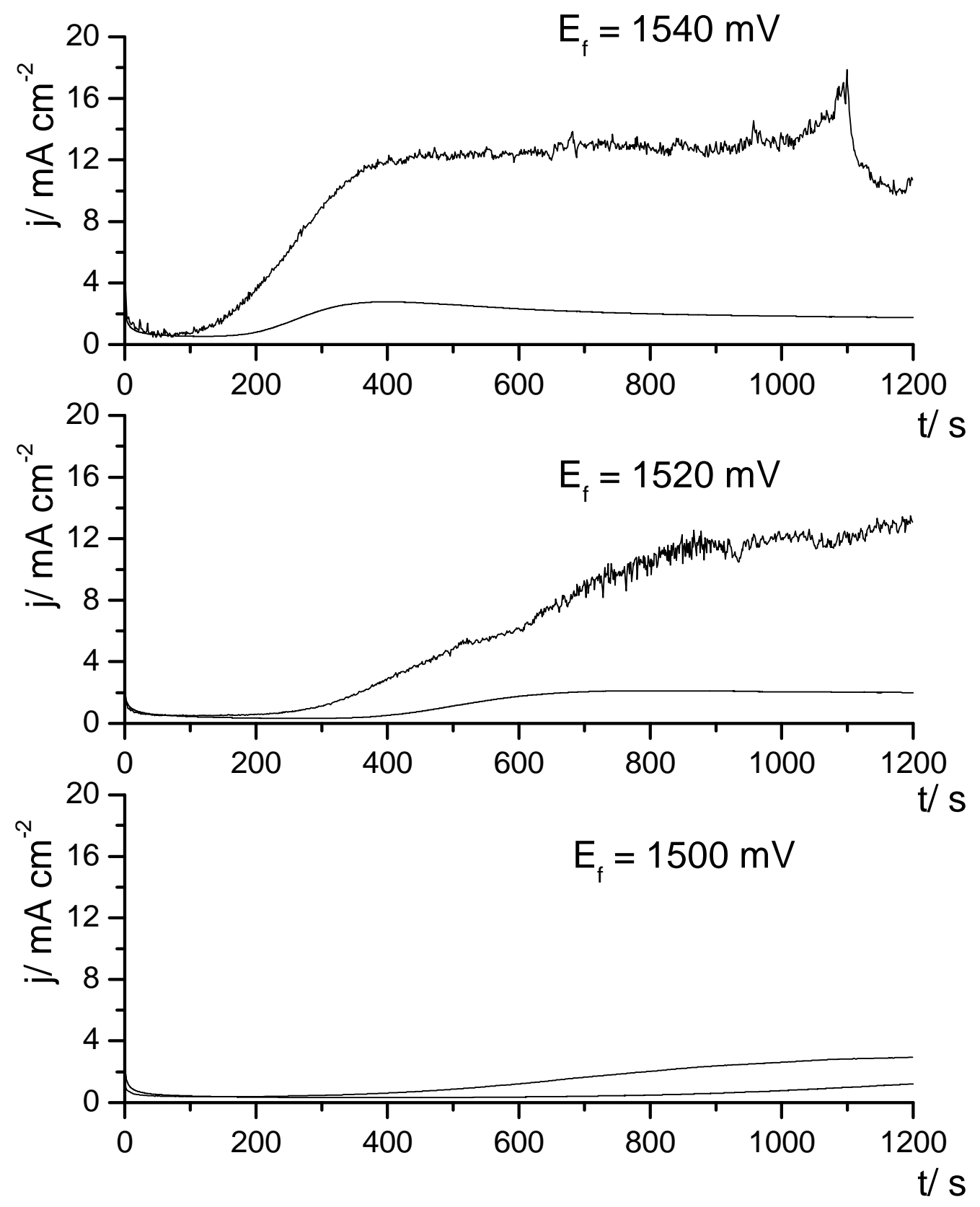

Figure 2.- Superposition of the chronoamperometric curves for $\mathrm{PbO}_{2}$ deposition in in $0.1 \mathrm{M} \mathrm{Pb}\left(\mathrm{NO}_{3}\right)_{2}+1 \mathrm{M} \mathrm{HNO}_{3}$ recorded under silent (taken from reference 24) and ultrasonic conditions. 


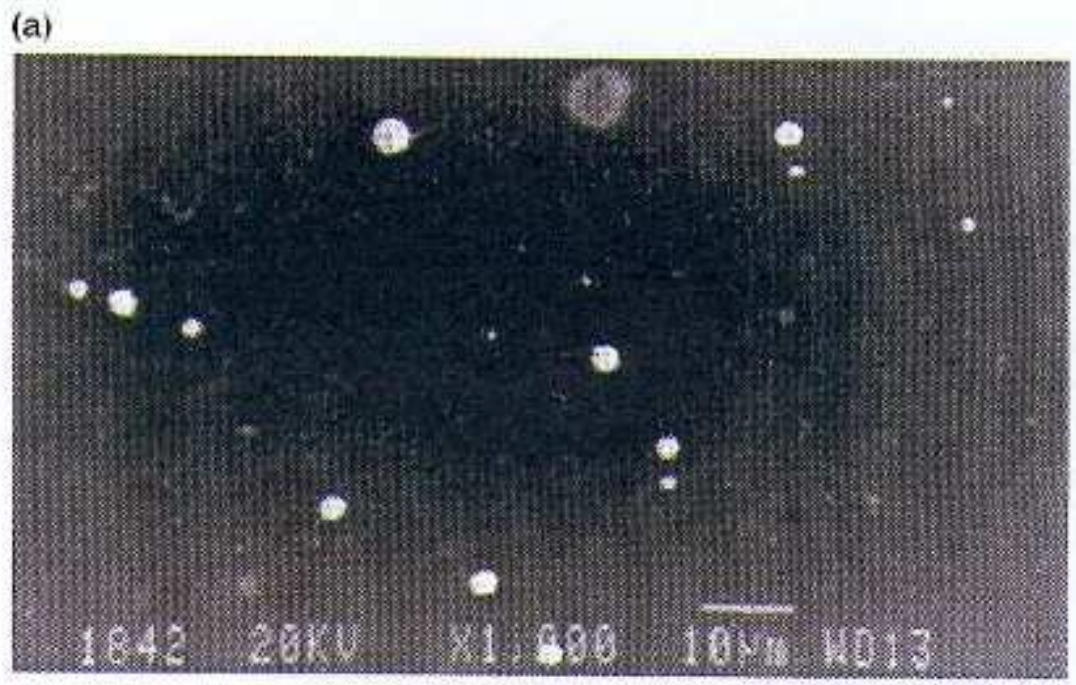

(b)

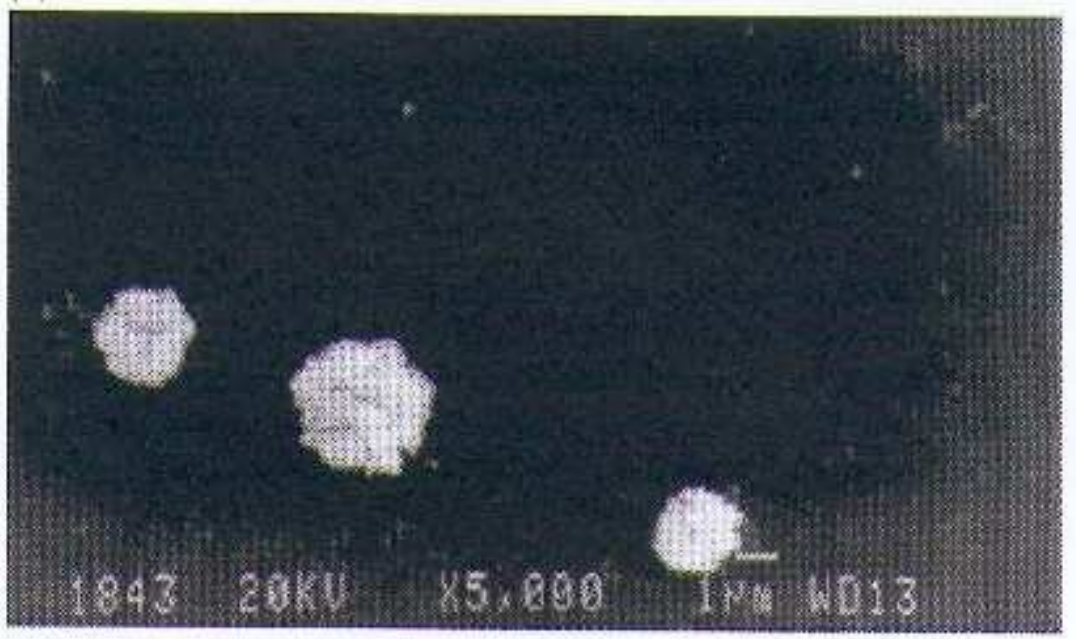

Figure 3. Scanning electron micrographs of the glassy cabon electrode at the first stages of the lead dioxide crystallization under ultrasounds. Magnification a) x1000; b) x5000. 

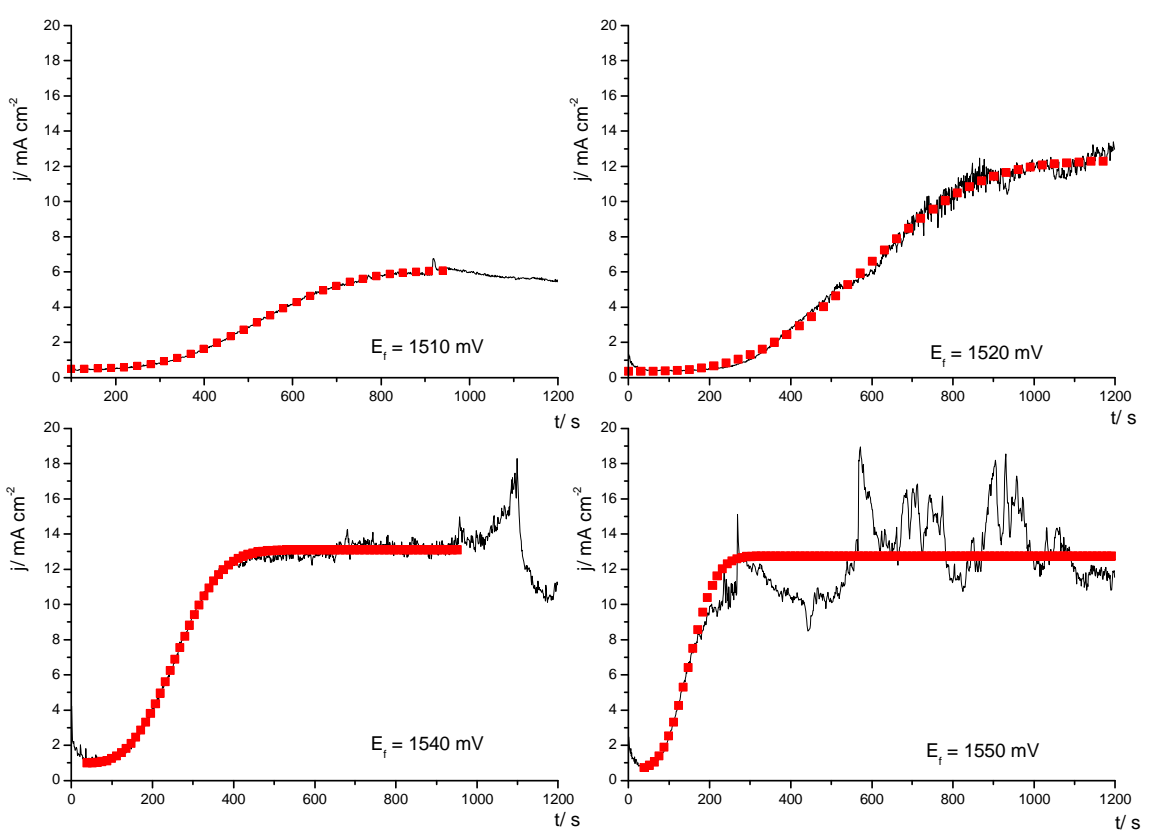

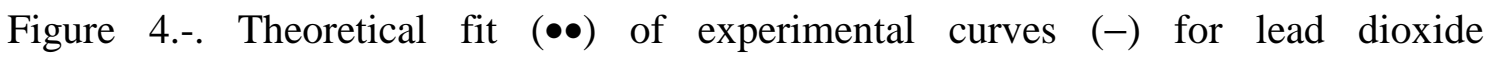
electrodeposition under ultrasound. 

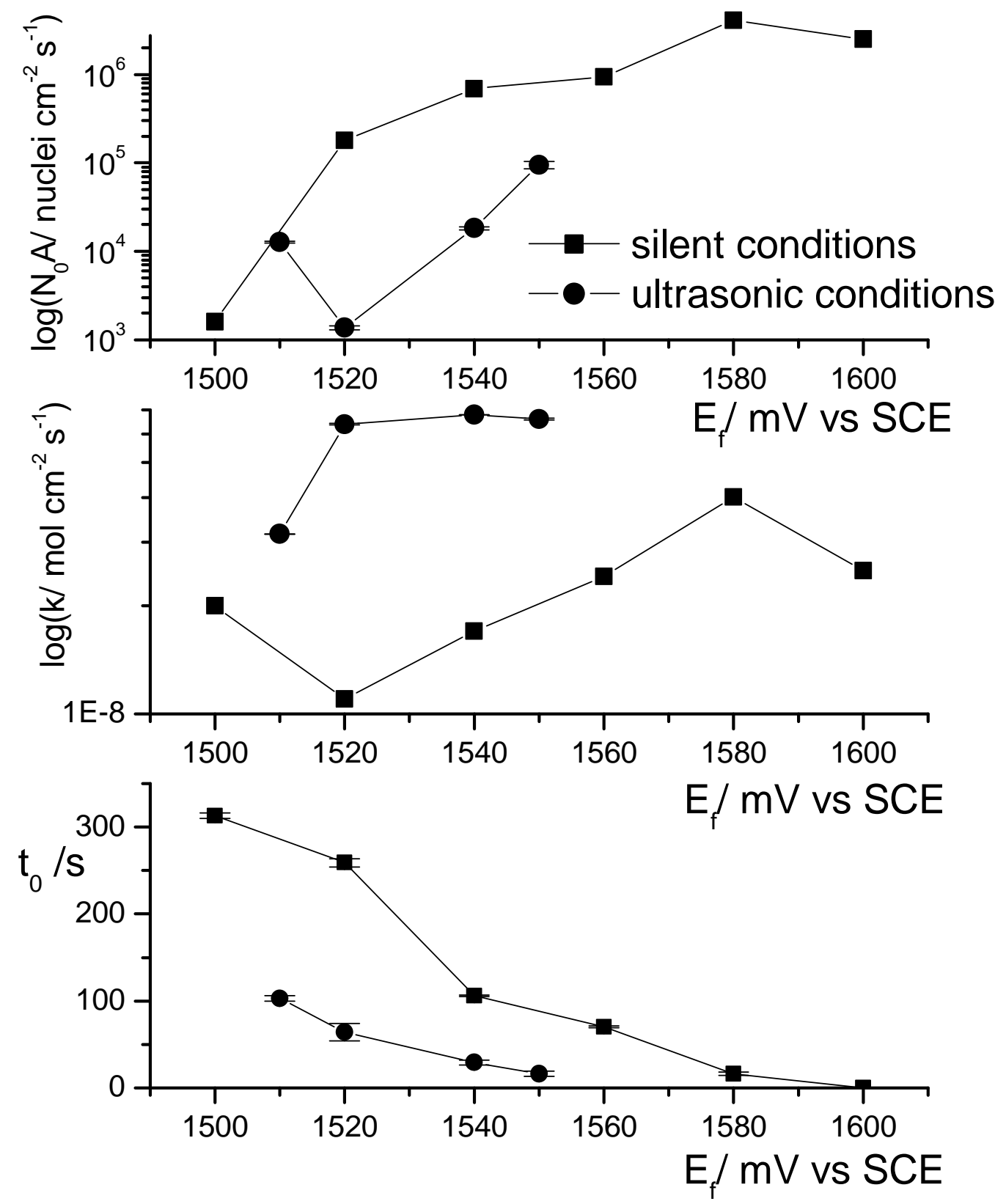

Figure 5.- Comparison of dependence of $\mathrm{t}_{0}, \log \mathrm{N}_{0} \mathrm{~A}$ and $\log \mathrm{k}$ on applied potential for lead dioxide electrodeposition in absence (taken from reference 24) and presence of ultrasound.

$\mathrm{E}_{\mathrm{f}} / \mathrm{mV} \quad \mathrm{j}_{0} / \mathrm{mA} \mathrm{cm}^{-2} \quad \mathrm{t}_{0} / \mathrm{s} \quad \mathrm{k} / \mathrm{mol} \mathrm{cm}^{-2} \mathrm{~s}^{-1} \quad \mathrm{~N}_{0} \mathrm{~A} /$ nuclei $_{\mathrm{cm}^{-2} \mathrm{~s}^{-1}} \quad \mathrm{chi}^{2}$ 


$\begin{array}{lcccccc}1510 & 0.505 \pm 0.008 & 103 \pm 3 & (3.163 \pm 0.005) 10^{-8} & (1.27 \pm 0.03) 10^{4} & 0.01 \\ 1520 & 0.37 \pm 0.03 & 64 \pm 10 & (6.39 \pm 0.02) 10^{-8} & (1.37 \pm 0.07) 10^{3} & 0.1 \\ 1540 & 0.99 \pm 0.04 & 29 \pm 3 & (6.785 \pm 0.007) 10^{-8} & (1.83 \pm 0.07) 10^{4} & 0.09 \\ 1550 & 0.69 \pm 0.09 & 16 \pm 3 & (6.60 \pm 0.04) 10^{-8} & (9.5 \pm 0.9) 10^{4} & 0.1\end{array}$

Table 1.- Kinetics parameters of electronucleation and growth of lead dioxide electrodeposition. 